\title{
BUTTERFLIES AND VERTEBRATE FAUNAL DIVERSITY OF THE AMBULUWAWA BIO-DIVERSITY COMPLEX
}

\author{
A M D B Alahakoon ${ }^{1}$ and V P K Samarawickrama² \\ 1 Department of Geography, University of Peradeniya \\ 2fUCN, Horton Place, Colombo 7
}

The Ambuluwawa Biodiversity Complex $(A B C)$ was created recently on the Ambuluwawa Hill (elevation: 1071 meters) situated close to the Gampola Town, Kandy District. Its habitats include: lowland rainforest patches, grasslands with exposed rocks, a Pinus plantation, newly designed gardens, and several artificial ponds.

The present study was carried out in this forest from $23^{\text {rd }}$ January to $20^{\text {th }}$ February of 2003 , with the objective of surveying the area's faunal diversity. The 'long transect method' was applied for faunal observations (both direct and indirect) along nature trails in the forest patches and the planted forest, whereas random traversing was done in the grassland. The observations were made once a week both in day and night times during the study period. The breadth of the long transect was restricted by the visibility determined by the daylight and night lamps. Binoculars were used to observe birds. In the study of herpetofauna, hand nets were used and the animals were released after identification. No ichthyofauna could be observed other than the introduced fish found in the artificial ponds.

The results suggest the presence of the following altogether: 11 mamalian species, including 01 endemic (within nine families),

59 avian species including 07 endemic species (within 31 families),

30 reptilian species including 13 endemic species (within eight families),

13 amphibian species including 06 endemic species (within three families) and

13 butterfly species including 02 endemic ones (within six families).

The total number is 126 species.

Out of the above, 29 endemic species, 28 are nationally threatened. Moreover, there are also two nationally threatened no-endemic species.

It appears that since, the recent development of the Bio Diversity Complex the fauna there is highly threatened due to the construction activities such as rock blasting, deforestation and road development etc. Furthermore, the presence of visitors also has a negative effect on the fauna.

Proceedings of the Ninth Annual Fonestry and Environment Symposium 2003 of the Department of Forestry and Environmental Science, University of Sri Jayewardenepura, Sri Lanka 